\section{Canadian Geotechnical Journal}

Published by

THE NATIONAL RESEARCH COUNCIL OF CANADA

\section{Revue canadienne de géotechnique}

Publiée par

LE CONSEIL NATIONAL DE RECHERCHES DU CANADA

\begin{tabular}{|c|c|c|c|c|}
\hline Volume 17 & Number 4 & November 1980 & Volume 17 & numéro \\
\hline
\end{tabular}

\title{
Screw plate testing of a soft clay
}

\author{
A. Patrick S. Selvadurai, Gunther E. Bauer, and Terrance J. Nicholas ${ }^{1}$ \\ Department of Civil Engineering, Carleton University, Ottawa, Ont., Canada K1S $5 B 6$
}

Received August 15, 1979

Accepted May 20, 1980

\begin{abstract}
The screw plate test was developed for the determination of the in situ deformability characteristics of both granular and cohesive soils. This paper examines several theoretical models that may be used to evaluate the in situ undrained deformability and shearing strength characteristics of a cohesive soil medium from results of screw plate tests. It is shown that the undrained modulus and the undrained shearing strength can be evaluated directly from the load-displacement response obtained from the screw plate test.
\end{abstract}

\begin{abstract}
L'essai de plaque vissée a été mis au point pour permettre la mesure des caractéristiques de déformation in situ des sols pulvérulents et cohérents. L'article présente un examen de plusieurs modèles théoriques qui peuvent être utilisés pour évaluer la déformabilité et la résistance au cisaillement non drainé in situ dans un sol cohérent à l'aide de l'essai de plaque vissée. On montre que le module non drainé et la résistance au cisaillement non drainé peuvent être obtenus directement de la loi charge-déplacement définie lors de l'essai de plaque vissée.
\end{abstract}

[Traduit par la revue]

Can. Geotech. J., 17, 465-472 (1980)

\section{Introduction}

It is generally recognized that sampling disturbances can introduce considerable errors in the laboratory estimation of geotechnical properties of sensitive cohesive soils (Eden 1970; La Rochelle and Lefebvre 1970; Raymond et al. 1971). The degree of sample disturbance can, however, be minimized by using high-quality samplers or large block samples (Eden 1970; Domaschuk 1977; Lefebvre and Poulin 1979). Such sample retrieval procedures are by no means routine. Furthermore, the sample disturbance associated even with efficient sampling procedures constitutes an unknown factor. It is therefore advantageous to adopt in situ techniques for the estimation of geotechnical properties. They provide valuable means for the correlation of laboratory parameters

IPresent address: Golder Associates, Ottawa, Ont., Canada K2C 2B5. derived from efficient sampling techniques. Comprehensive accounts of in situ tests (such as shallow and deep plate load tests, pressure meter tests, screw plate and other penetration tests) in both cohesive and cohesionless soils are given by Sanglerat (1972), Mitchell and Gardner (1975), Wroth (1975), Marsland and Randolph (1977), Baguelin et al. (1977), and Ladd et al. (1977). The screw plate test is a recent variation of the conventional plate load test, which has been utilized for the measurement of in situ geotechnical properties of both cohesive and cohesionless soils (Fig. 1). The test plate is basically a single cycle of a helical auger, which is inserted into the soil medium. Early applications of the screw plate test, as described by Kummeneje and Eide (1961), were primarily concerned with its use as a sounding device to observe the change in density of loose sand deposits due to blast effects. Further field studies of screw plate testing of granular soil deposits are 


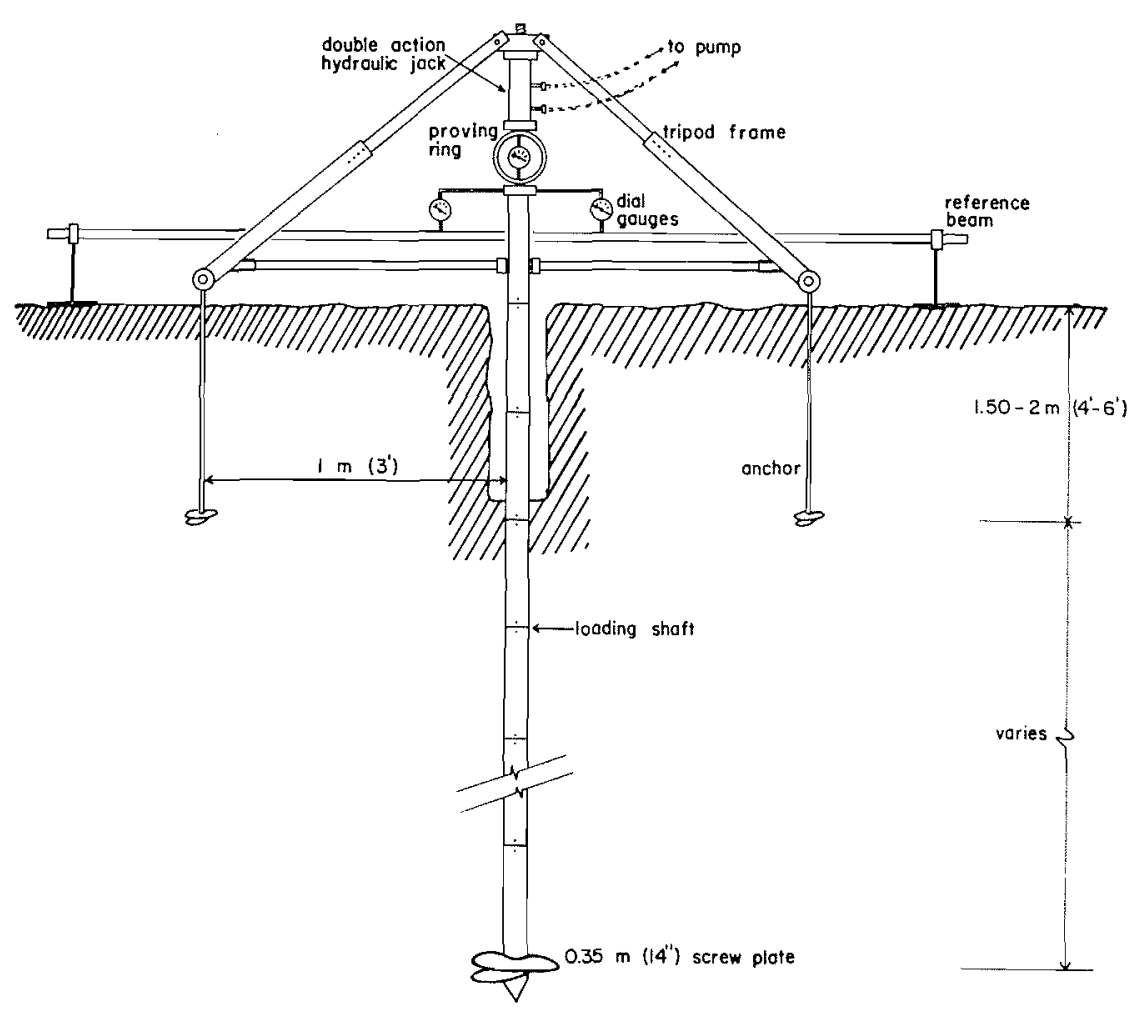

FIG. 1. Schematic view of the Carleton University screw plate device.

reported by Gould (1967). Schmertmann (1970) and Janbu and Senneset (1972) have used the screw plate test to measure the in situ deformability characteristics of cohesionless soil deposits. Dahlberg (1975) has used the test to ascertain the influence of precompression on the deformability of granular soils. More recently, studies involving time-independent and time-dependent screw plate testing of silty clays were reported by Schwab (1976) and Schwab and Broms (1977).

Since the primary application of the screw plate test has been extensively concerned with testing in granular soil deposits, the interpretation of the test results invariably involved empirical assumptions. The empiricism that is usually associated with the treatment of settlement and deformations in granular soils (Sutherland 1975; Burland 1977) has therefore prompted the use of similar relationships for the estimation of "moduli of deformation" from screw plate tests. When dealing with screw plate tests conducted in cohesive soils, the deformability and strength characteristics can be estimated by recourse to certain simplified theories of material behaviour, such as linearized elasticity and ideal plasticity. Such theories provide useful descriptions of the undrained response of cohesive soils at working and ultimate load levels. Furthermore, since the geotechnical parameters predicted by such theories are invariant material properties the results from various in situ tests (such as screw plate and pressure meter tests) permit comparison.

This paper presents the results of some preliminary screw plate tests conducted at the Gloucester test fill site (Bozozuk and Leonards 1972). The performance of the screw plate test is examined in the light of the classical theories of isotropic elasticity and ideal plasticity. The relationships proposed here can be utilized to determine the undrained elastic modulus and the undrained shear strength of a cohesive soil from the load-displacement results measured in a screw plate test.

\section{The Undrained Modulus from Screw Plate Tests}

The screw plate, like any other penetrating in situ testing device, causes some soil disturbance during its installation. The extent of this soil disturbance can be quantified only in rare cases. The stress paths associated with either the alteration of the in situ state of stress or the nonhomogeneity created by the altera- 


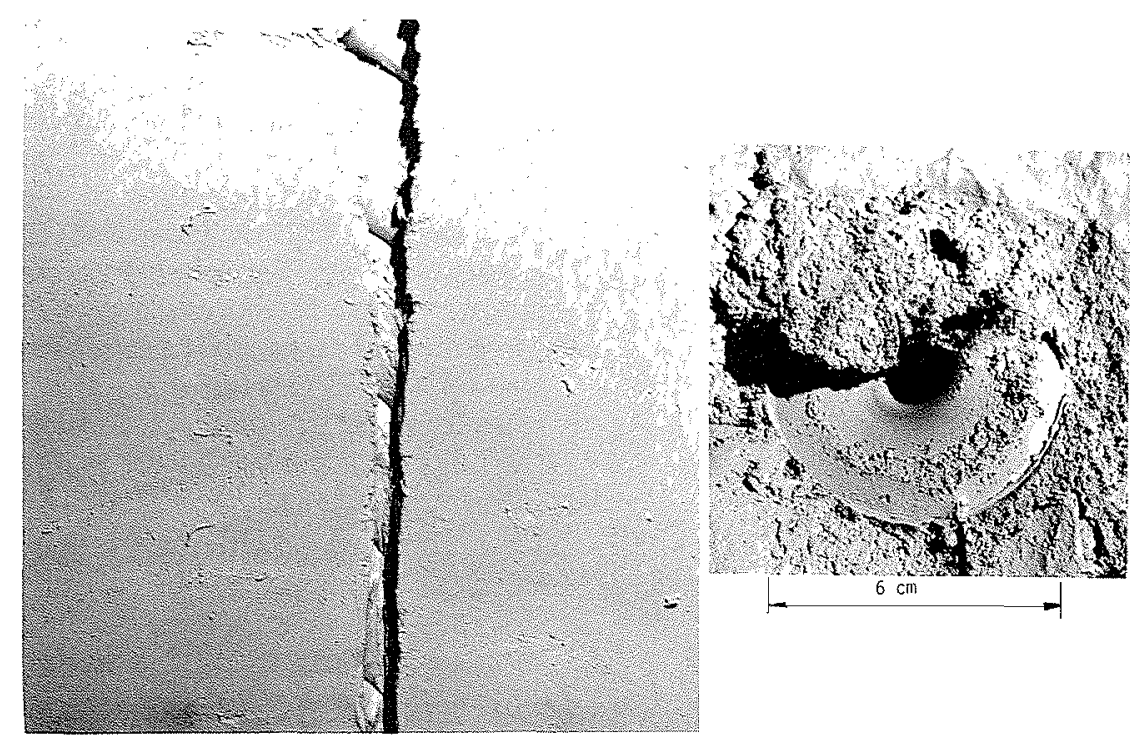

FIG. 2. Driven path of a model screw plate in compacted kaolin.

tion of material characteristics along the driven path of the test device are open to conjecture in any form of in situ testing. With regard to the screw plate test, these soil disturbances are probably no more severe than the penetration action of the Camkometer (or similar device) in an otherwise unlined borehole. Laboratory studies (Selvadurai et al. 1980) conducted with a model screw plate inserted into a stratum of compacted kaolin indicate that there is no severe straining of the compacted material due to the penetration action of the helical plate (Fig. 2). These effects can be minimized by assigning suitable proportions to the diameter of the loading shaft $(2 c)$, the diameter of the screw plate ( $2 a)$, the thickness of the plate $(t)$, and the pitch $(2 b)$. (For example, in the investigations performed the various aspect ratios were: $c / a \simeq 0.125 ; b / a \simeq 0.25 ; t / a \simeq 0.02$.) After insertion to the required depth, the screw plate load test will examine a region of the soil that is relatively unaffected by the driving action. Also, during the driving of the screw plate there is little or no stress relief by any process similar to the removal of overburden stresses.

The above considerations associated with the soil disturbance, together with other factors relating to conditions at the soil - screw plate interface, the flexibility of the plate, and the helical nature of the test plate, etc., make it necessary to consider a catalogue of plausible theoretical models from which the undrained in situ deformability characteristics can be inferred. These results discussed in this section are derived from (i) exact mathematical solutions, (ii) approximate solutions based on variational methods, and (iii) finite element solutions. From these investigations it becomes evident that certain bounds can be assigned for the in situ undrained modulus as inferred from the results of screw plate tests. A full account of the theoretical developments is given by Selvadurai and Nicholas (1979).

A theoretical problem concerning the estimation of the undrained deformability characteristics from the results of screw plate tests can be formulated as an axisymmetric problem in the classical theory of elasticity, where a circular plate-like region embedded in a homogeneous isotropic elastic medium is subjected to an axial load. In such a theoretical development the following factors should be given due consideration.

\section{(i) The Elastic Medium}

In the theoretical developments, the screw plate is assumed to be located in an elastic medium of infinite extent. This is due to the fact that the screw plate test is usually carried out at a depth substantially greater than the diameter of the plate; available theoretical results (Butterfield and Banerjee 1971; Hunter and Gamblen 1974; Selvadurai 1978) indicate that when the test plate is located at a depth greater than 6-8 diameters, the effect of the free boundary on the deflection of the plate is almost negligible. Practical considerations would indicate that screw plate tests carried out near ground level are essentially plate load tests.

\section{(ii) The Test Plate}

The circular area over which the applied loads are transmitted to the cohesive soil may be assumed to 


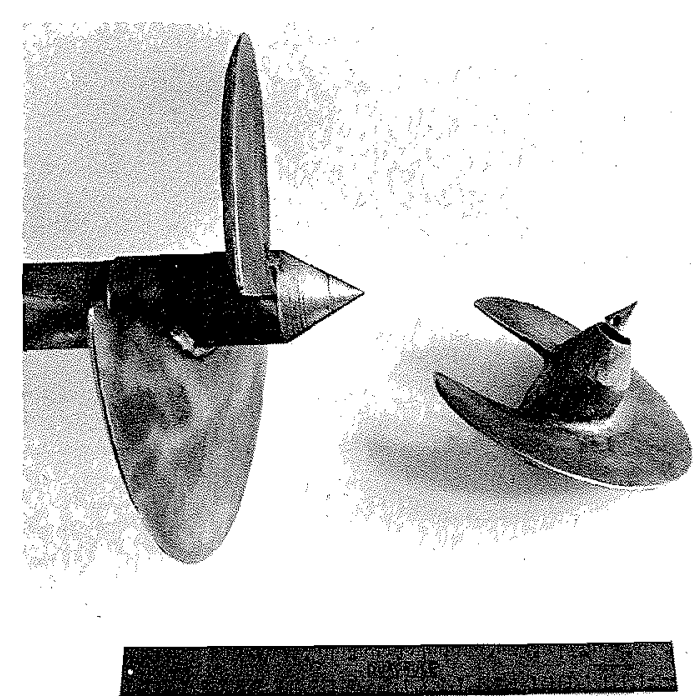

FrG. 3. Screw plates used in field testing.

be completely flexible, infinitely rigid, or possessing finite flexural rigidity characteristics commensurate with the plate dimensions and its elastic characteristics. The effect of the helical nature of the test plate may also have an influence on the effective plate dimensions (Fig. 3). In this instance the behaviour of the test plate may be approximated by that of a rigid spheroidal region embedded in the elastic medium.

(iii) The Soil-Plate Interface

In practice the interface between the soil medium and the screw plate can exhibit a variety of interface phenomena ranging from complete adhesion (or bonded) to the completely frictionless (or smooth), with Coulomb friction or finite friction occupying an intermediate position. The analysis of the latter class of effects is mathematically complex. For example, the analysis of elastic contact problems, which exhibit frictional interface phenomena with finite frictional forces, can be obtained via an incremental analysis (see, e.g., de Pater and Kalker 1975). The results corresponding to perfectly bonded and smooth interfaces therefore provide probable limits for the assessment of screw plate test results. In addition it is also possible to visualize a situation wherein bonding exists only on one plane face of the screw plate and the other detaches itself from the soil region.

\section{(iv) Soil Disturbance}

As discussed previously, the driving action of the screw plate causes, by its cutting action, a certain degree of soil disturbance. The influence of this disturbance on the measured in situ deformability characteristics can be assessed by adopting the finite element method. In the extreme case it is assumed that the extent of soil disturbance is such that the cylindrical column of soil along the driven path of the screw plate possesses zero stiffness. In this instance, the screw plate test degenerates to a plate load test carried out at the base of an unlined borehole.

Estimates for the Undrained Elastic Modulus $\mathrm{E}_{u}$

The numerical results derived from the various theoretical models of the screw plate performance are summarized in Table 1. From these results it becomes evident that bounds can be established for the estimation of the in situ undrained modulus from results of screw plate tests. For the undrained elastic behaviour of the cohesive soil medium, the range of $E_{\mathrm{u}} w / p a$ (where $w$ is the plate settlement; $p$ is the applied

TABLE 1. Estimation of undrained modulus from screw plate tests

\begin{tabular}{|c|c|c|c|}
\hline Solution & $\frac{w}{p a / E_{\mathbf{u}}}$ & Reference & Remarks \\
\hline (a) & 0.630 & Kelvin (1890) & Average displacement of uniform load \\
\hline (b) & 0.589 & $\begin{array}{l}\text { Collins (1962), Kanwal and } \\
\text { Sharma (1976), Selvadurai (1976) }\end{array}$ & Displacement of fully bonded rigid disc \\
\hline (c) & 0.750 & Hunter and Gamblen (1974) & Displacement of smoothly embedded rigid disc \\
\hline (d) & 0.750 & Keer (1975) & Displacement of partially bonded rigid disc \\
\hline (e) & 0.648 & Selvadurai $(1979 a, b)$ & Central displacement of flexible disc* \\
\hline (f) & 0.585 & Selvadurai (1976) & Displacement of rigid spheroidal region $\dagger$ \\
\hline (g) & 0.730 & $\begin{array}{l}\text { Christian and Carrier (1978), } \\
\text { Pells and Turner (1978) }\end{array}$ & Average displacement of deep borehole subjected to uniform load \\
\hline (h) & 0.525 & $\begin{array}{l}\text { Christian and Carrier (1978), } \\
\text { Pells and Turner (1978) }\end{array}$ & Displacement of rigid plate at base of deep borehole \\
\hline
\end{tabular}

Nores: $a$ is radius of screw plate; $p$ is average stress on screw plate $=P / \pi a^{2} ; E_{\mathrm{u}}$ is undrained modulus.

Relative rigidity of plate

$R=\frac{\pi(3-4 \nu)(1+\nu)}{12\left(1-\nu_{\mathrm{p}}\right)(1-\nu)} \frac{E_{\mathrm{p}}}{E}\left(\frac{h}{a}\right)^{3}=10$

where $h$ is thickness of screw plate; and $E_{\mathrm{p}}, \nu_{\mathrm{p}}$ are the elastic constants for the plate material.

tScrew plate of half pitch to diameter ratio of 0.125 . 
stress; $a$ is the radius of the screw plate; $E_{\mathrm{u}}$ is the undrained elastic modulus) applicable for the screw plate test varies from 0.750 to 0.525 . Both these results relate to physically admissible interpretations of the screw plate test performance. The lower limit admits a situation where there is complete loss of soil strength and stiffness along the driven path of the screw plate (such a situation could conceivably occur if the screw plate were power driven into a deposit of highly sensitive clay). In the authors' opinion, however, this assumption is perhaps too stringent a restriction on the performance of the screw plate test. The remaining set of theoretical models provides the following approximate result for the assessment of the undrained deformability characteristics of a cohesive soil medium from results of screw plate tests:

[1] $w /\left(p a / E_{\mathrm{u}}\right) \simeq 0.60-0.75$

The accuracy and reliability of the above estimates can be established only by recourse to comparison with equivalent results derived from other in situ tests such as the pressure meter test or from laboratory tests conducted on relatively undisturbed samples of the cohesive soil medium. Unlike the previous investigations of the screw plate test (Janbu and Senneset 1973; Dahlberg 1975; Schwab 1976; Schwab and Broms 1977) the above result places the estimation of $E_{\mathrm{u}}$ from screw plate tests on a sound theoretical footing (at least within the assumptions of idealized linear elastic behaviour), thereby providing a basis for comparison with results of modulus values derived from other classes of in situ tests such as the pressure meter test.

\section{The Undrained Shear Strength from Screw Plate Tests}

This section presents a theoretical basis for the estimation of the in situ undrained shear strength of the cohesive soil $\left(c_{\mathrm{u}}\right)$ from the ultimate load recorded in the screw plate test. As has been observed by Schwab (1976) and Schwab and Broms (1977) the effect of sinkage of the screw plate is to make the failure load less discernable. To eliminate this am- biguity in the definition of the limit load it is convenient to adopt a modified plot of the load-settlement curve for the screw plate test wherein the average stress is plotted in a logarithmic scale and the plate settlement is expressed as a percentage of the plate diameter. A failure load can then be defined as either the peak value of the modified pressuresettlement curve or the pressure at which the slope of the load-settlement curve changes abruptly. The failure load $\left(P_{\mathrm{ult}}\right)$ recorded is related to the undrained shearing strength of the cohesive soil by appeal to theoretical solutions based on ideal plasticity. Table 2 summarizes a set of parameters for $p_{\mathrm{ult}} / c_{\mathrm{u}}$ (where $p_{\mathrm{ult}}=P_{\mathrm{ult}} / \pi a^{2}$ ) that may be utilized to estimate $c_{\mathrm{u}}$. For example, the results by Shield (1955) and Eason and Shield (1960) are based on classical plasticity solutions that invoke the Harr von Karman postulate (i.e., the circumferential stress $\sigma_{\theta \theta}$ in the axisymmetric problem is set equal to the algebraic value of one of the principal stresses derived from the stress system $\sigma_{r r}, \sigma_{z z}$, and $\sigma_{r z}$ ). Also in the case of a purely cohesive soil, the MohrCoulomb yield condition can be identified with the Tresca yield condition. The result of Meyerhof (1951) is based on Hencky's approximate method involving a plane strain slip-line field. Skempton's (1951) result is developed for the analysis of deep circular foundations. It may be observed that these results essentially correspond to the loading of a circular plate at the base of an unlined borehole. The results by Selvadurai and Szymanski (1980) are also based on classical plasticity solutions developed for smooth and rough circular rigid anchor plates embedded in a cohesive soil medium. Here again, the Harr - von Karman postulate $\left(\sigma_{1}=\sigma_{2}=\sigma_{\theta \theta}\right)$ is invoked to render the problem statically determinate. In this discussion only a few solutions based on idealized plastic behaviour have been examined; other solutions developed for cavity expansion problems could no doubt find useful application.

\section{Estimates for the Undrained Shear Strength $\mathrm{c}_{u}$} Considering the theoretical results given in Table 2

TABLE 2. Estimation of undrained shear strength from screw plate tests

\begin{tabular}{ccll}
\hline \hline Solution & $p_{\mathrm{ult}} / c_{\mathrm{u}}$ & \multicolumn{1}{c}{ Reference } & \multicolumn{1}{c}{ Remarks } \\
\hline (a) & 5.69 & Shield (1955) & Rigid circular punch on half-space-smooth interface \\
(b) & 6.05 & Eason and Shield (1960) & Rigid circular punch on half-space-rough interface \\
(c) & 9.00 & Skempton (1951) & Circular foundation at large depth-empirical \\
(d) & 9.34 & Meyerhof (1951) & Circular foundation at large depth-approximate \\
& & solution-rough interface \\
(e) & 10.97 & Selvadurai and Szymanski (1980) & Deeply embedded rigid circular plate-smooth interface \\
(f) & 11.35 & Selvadurai and Szymanski (1980) & Deeply embedded rigid circular plate-rough interface \\
\hline
\end{tabular}

NOTES: $p_{\text {utt }}$ is failure stress; $c_{u}$ is undrained shear strength. 
it is evident that the solutions (a) and (b) are of limited interest in the estimation of $c_{\mathrm{u}}$ from screw plate tests. These solutions are presented only for purposes of comparison. Furthermore, these solutions, developed for the ideally plastic half-space problem, disregard the shear strength that can be mobilized in the upper half-space region (i.e., the region located above the plane of the screw plate). A comparison of (a) and (b) with (c)-(f) clearly indicates the significance of the contribution of the upper half-space region to $P_{\text {ult }}$. The theoretical solutions (c)-(f) give the following bounds for the assessment of the undrained shear strength of a cohesive soil medium from the ultimate load derived from a screw plate test:

[2] $p_{\mathrm{ult}} / c_{\mathrm{u}} \simeq 9.00-11.35$

\section{Field Studies}

This section describes the results of some preliminary screw plate tests conducted at a test fill site adjacent to the Canadian Forces Station (CFS) Gloucester, near Ottawa, Ontario. The test fill constructed at this site has been the subject of extensive field and laboratory investigations (see, e.g., Bozozuk and Leonards 1972; Lo et al. 1976). The screw plate tests were carried out at a location approximately $10 \mathrm{~m}$ from the edge of the fill and in the vicinity of the minor central axis of the fill (see Fig. 4). Briefly, the soil profile of the site in this region (Fig. 4) consists of a surface crust terminating abruptly at a depth of approximately $1.8 \mathrm{~m}$ with the lower $0.9 \mathrm{~m}$ composed of a medium-stiff fissured clay. The crust rests on a soft silty clay layer of thickness approximately $0.75 \mathrm{~m}$ containing organic matter. The underlying grey silty marine clay extends to a depth of approximately $18 \mathrm{~m}$. A more complete account of the index properties of the various strata, together with their in situ undrained shear strength characteristics, may be found in Bozozuk and Leonards (1972). In addition, the above authors report results of undrained modulus measurements carried out on very highquality triaxial samples obtained with the Norwegian Geotechnical Institute (NGI) and Osterberg samplers. These results indicate that, for the deep deposit of grey clay, the undrained elastic modulus approximately corresponds to the empirical relationship $E_{\mathrm{u}} \simeq 630 c_{\mathrm{u}}$ in the upper region and $E_{\mathrm{u}} \simeq 1070 c_{\mathrm{u}}$ in the lower region. Since the screw plate tests were conducted in the upper region of the grey clay stratum (maximum depth of test $4 \mathrm{~m}$ ) it would appear that the undrained elastic modulus as inferred from the shear strength data of Bozozuk and Leonards and the above empirical relationships
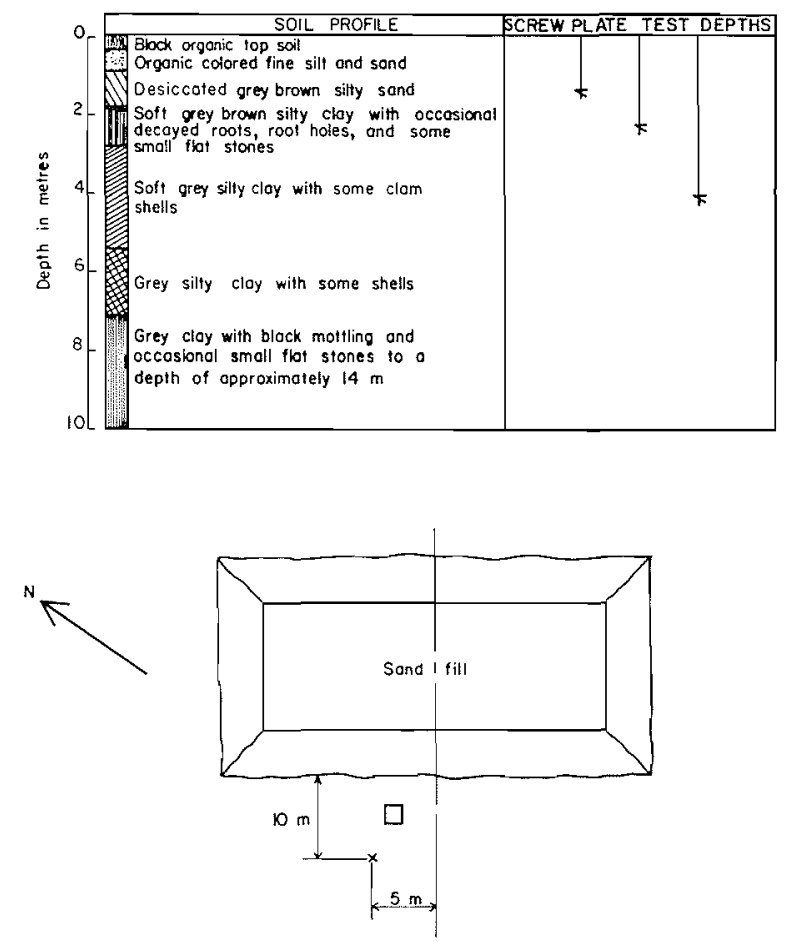

FIG. 4. Gloucester test fill site-location of screw plate tests.

would approximately correspond to $(6-8) \times 10^{3} \mathrm{kPa}$ at the $2.3 \mathrm{~m}$ depth and $(12-15) \times 10^{3} \mathrm{kPa}$ at the $4.1 \mathrm{~m}$ depth.

Two screw plate tests were performed at this site at depths of approximately 2.0 and $4.0 \mathrm{~m}$. The initial metre of the organic matter was removed by a $0.2 \mathrm{~m}$ diameter auger to facilitate the driving of the screw plate. The screw plate was inserted into the soil medium manually. A probable ultimate load for the plate was established a priori by using the shear strength data given by Bozozuk and Leonards (1972) and [2]. The screw plate was subjected to a maximum load not greater than one third this ultimate value. Before commencement of the test the screw plate was subjected to a priming load of approximately $1.3 \mathrm{kN}$. Each subsequent load increment was maintained for a period of $2 \mathrm{~min}$. The field tests performed thus far display no tendency for any accelerated creep. Figure 5 shows the typical load-displacement cycles measured for screw plates located at approximately 2 and $4 \mathrm{~m}$ depths, respectively. The first cycle of these load-settlement curves indicates the possibility of the occurrence of some disturbance either due to the smearing action of the driven plate or bedding errors in the test procedure. The second cycle of each screw plate test is used for the estimation of the undrained deformability characteristics of the grey clay. Fur- 

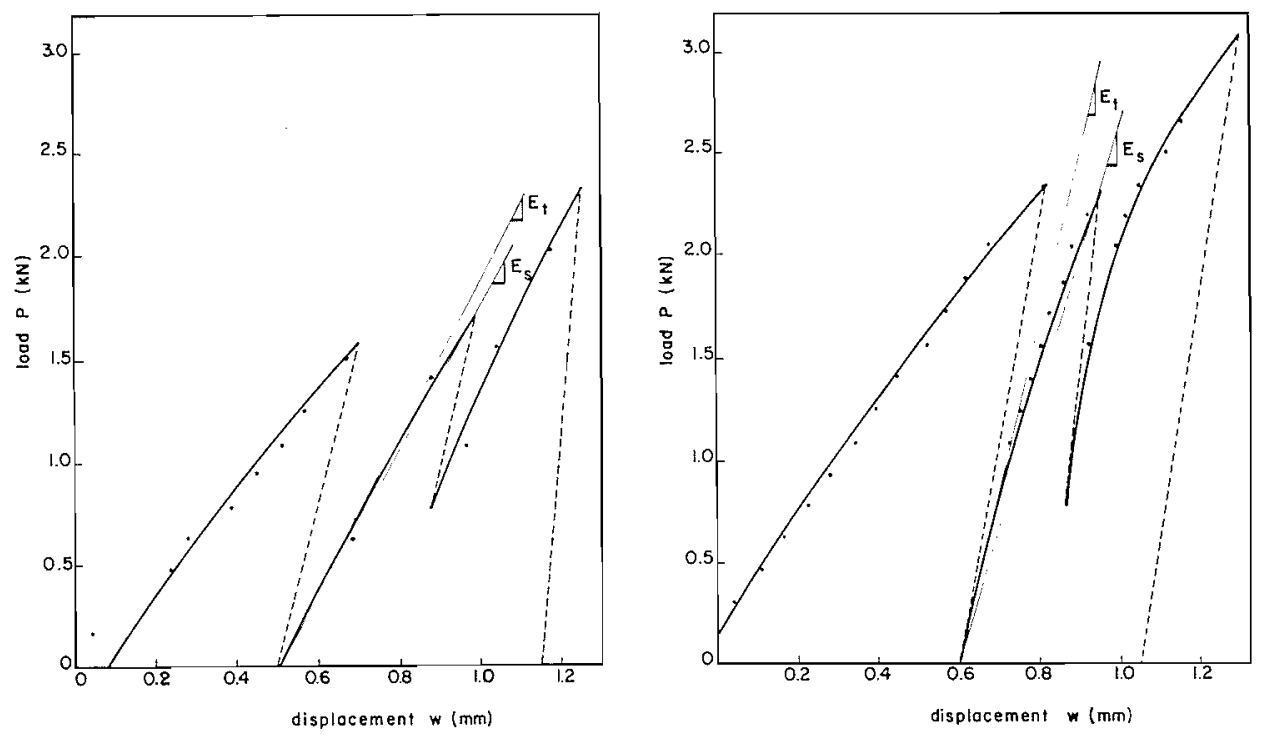

FIG. 5. Load-settlement curves for the screw plate test.

TABLE 3. Summary of results for the undrained modulus

\begin{tabular}{|c|c|c|c|c|c|}
\hline \multirow{2}{*}{$\begin{array}{l}\text { Depth } \\
\text { (m) }\end{array}$} & \multicolumn{2}{|c|}{$E_{\mathrm{u}}=0.6 P / \pi a w$} & \multicolumn{2}{|c|}{$E_{u}=0.75 P / \pi a w$} & \multirow{2}{*}{$\begin{array}{c}E_{\mathrm{u}} \text { estimated } \\
\text { from } \\
\text { shear strength } \\
\text { data }\end{array}$} \\
\hline & Tangent & Secant & Tangent & Secant & \\
\hline 2 & 5.0 & 4.5 & 6.1 & 5.6 & $6.0-8.0$ \\
\hline 4 & 13.5 & 9.6 & 17.0 & 12.0 & $12.0-15.0$ \\
\hline
\end{tabular}

Notes: All modulus values are in units of $10^{3} \mathrm{kPa} ; E_{4} \simeq 630 c_{u}$; at a depth of $2.3 \mathrm{~m}, c_{u} \simeq 10 \mathrm{kPa}$; at a depth of $4.1 \mathrm{~m}, c_{v} \simeq 20 \mathrm{kPa}$.

thermore, two sets of modulus values can be evaluated corresponding to the secant or tangent modulus for the second loading curve. A summary of these modulus values is presented in Table 3. These preliminary tests were performed with a view to estimating the undrained deformability characteristics of the soft clay. As such, the loads applied were well below those required for the determination of in situ values of $c_{u}$.

\section{Conclusions}

This paper outlines the possible analytical models that can be utilized to estimate, from the results of a screw plate test, the undrained modulus and undrained shear strength values of a relatively homogeneous isotropic cohesive soil medium. The theoretical formulations are used to examine the results of some preliminary screw plate tests conducted at the CFS Gloucester site. The estimates for the undrained modulus values appear to be generally in agreement with results inferred from empirical relationships based on shear strength data.

\section{Acknowledgements}

The research described in this paper was supported by a National Research Council of Canada grant A3866, awarded to the senior author. The Faculty of Graduate Studies and Research at Carleton University also contributed to this research programme.

Baguelin, F., Jezequel, J. F., and Shields, D. H. 1977. The pressuremeter and foundation engineering. Trans Tech Publications Clausthall-Zehlerfeld, Germany.

Bozozuk, M., and Leonards, G. A. 1972. The Gloucester test fill. ASCE Specialty Conference on Performance of Earth and Earth-supported Structures, Purdue University, Lafayette, IN, Vol. 1(1), pp. 299-317.

Burland, J. B. 1977. Settlement of granular materials. Proceedings, 9th International Conference on Soil Mechanics and Foundation Engineering, Tokyo, Vol, 2, pp. 517-518.

BUTTERFIELD, R., and BANERJEe, P. K. 1971. A rigid disc of any shape embedded in an elastic halfspace. Geotechnical Engineering, 2, pp. 35-52.

Christian, J. T., and Carrier, W. D., III. 1978. Janbu, Bjerrum and Kjaernsli's chart reinterpreted. Canadian Geotechnical Journal, 15, pp. 123-128.

Collins, W. D. 1962. Some axially symmetric stress distributions in elastic solids containing penny shaped cracks. I. Cracks in an infinite solid and a thick plate. Proceedings of the Royal Society of London, Series A., 203, pp. 359-386.

DAhlberG, R. 1975. Settlement characteristics of preconsolidated natural sands. National Swedish Institute for Building Research, Stockholm, Sweden. Report ISBN 91-540-2410-2. de Pater, A. D., and Kalker, J. J., editors. 1975. The mechanics of contact between deformable bodies. Proceedings, International Union of Theoretical and Applied Mechanics Symposium, Enschede, The Netherlands, Delft University Press, Delft, The Netherlands.

Domaschuk, L. 1977. Soil block sampler. Canadian Geotechnical Journal, 14, pp. 262-265.

EDEN, W. J. 1970. Sample trials in overconsolidated sensitive 
clay. American Society for Testing and Materials, Special Technical Publication 483, pp. 132-142.

EASON, G., and SHIELD, R. T. 1960. The plastic indentation of a semi-infinite solid by a perfectly rough circular punch. Journal of Applied Mathematics and Physics, 11, pp. 33-43.

GouLD, J. H. 1967. The comparative study of screw plate and rigid plate bearing tests. M.S. thesis, University of Florida, Gainesville, FL.

Hunter, S. C., and Gamblen, D. 1974. The theory of a rigid circular disc ground anchor buried in an elastic soil either with adhesion or without adhesion. Journal of the Mechanics and Physics of Solids, 22, pp. 371-399.

JANBU, N., and SenNeSET, K. 1973. Field compressometer: principles and applications. Proceedings, 8th International Conference on Soil Mechanics and Foundation Engineering, Moscow, Vol. 1, pp. 191-198.

Kanwal, R. P., and Sharma, D. L. 1976. Singularity methods for elastostatics. Journal of Elasticity, 6, pp. 405-418.

KEER, L. M. 1975. Mixed boundary value problems for a penny-shaped cut. Journal of Elasticity, 5, pp. 89-98.

KELVIN, LORD. 1890. Mathematical and physical papers. Vol. 1. Cambridge University Press, London, England.

KuMMENEJE, O., and EIDE, O. 1961. Investigation of loose sand deposits by blasting. Proceedings, 5th International Conference on Soil Mechanics and Foundation Engineering, Paris, Vol. 2, pp. 491-497.

LadD, C. C., Foott, R., Ishihara, K., Schlosser, F., and Poulos, H. G. 1977. Stress deformation and strength characteristics. State-of-the-art Report. Proceedings, 9th International Conference on Soil Mechanics and Foundation Engineering, Tokyo, Vol. 2, pp. 421-494.

La Rochelle, P., and Lefebvre, G. 1970. Sampling disturbance in Champlain clays. American Society for Testing and Materials, Special Technical Publication 483, pp. 143-163.

LeFebvre, G., and Poulin, C. 1979. A new method of sampling in sensitive clay. Canadian Geotechnical Journal, 16, pp. 226-233.

Lo, K. Y., Bozozuk, M., and Law, K. T. 1976. Settlement analysis of the Gloucester test fill. Canadian Geotechnical Journal, 13, pp. 339-354.

Marsland, A., and Randolph, M. F. 1977. Comparison of the results from pressuremeter tests and large $i$-situ plate tests in London clay. Géotechnique, 27, pp. 217-243.

MeyerhoF, G. G. 1951. The ultimate bearing capacity of foundations. Géotechnique, 2, pp. 301-322.

Mitcherl, J. K., and Gardner, W. S. 1975. In-situ measurement of volume change characteristics. Proceedings, ASCE Specialty Conference on In Situ Measurement of Soil Properties, Raleigh, NC, Vol. 2, pp. 279-345.

Pells, P. J. N., and TuRner, R. M. 1978. Janbu, Bjerrum and Kjaernsli's chart reinterpreted: Discussion. Canadian Geotechnical Journal, 15, pp. 436-437.
RAYMOND, G. P., TOWNSEND, D. L., and LoJKASEK, M. J. 1971 The effect of sampling on the undrained soil properties of a Leda soil. Canadian Geotechnical Journal, 8, pp. 546-557.

SANGLERAT, G. 1972. The penetrometer and soil exploration. In Developments in geotechnical engineering. Vol. 1. Elsevier Scientific Publishers, Amsterdam, The Netherlands.

SchmertmanN, J. H. 1970. Static cone to compute static settlement over sand. ASCE Journal of the Soil Mechanics and Foundations Division, 97(SM3), pp. 1011-1043.

Schwab, E. F. 1976. Bearing capacity, strength and deformation behaviour of soft organic sulphide soils. Dept. of Soil Mechanics and Rock Mechanics, Royal Institute of Technology, Stockholm, Sweden.

Schwab, E. F., and Broms, B. B. 1977. Pressure-settlementtime relationship by screw plate tests in situ. Proceedings, 9th International Conference on Soil Mechanics and Foundation Engineering, Tokyo, Vol. 1, pp. 281-288.

Selvadurai, A. P. S. 1976. The load-deflexion characteristics of a deep rigid anchor in an elastic medium. Géotechnique, 26, pp. 603-612.

1978. The response of a deep rigid anchor due to undrained elastic deformations of the surrounding soil medium. International Journal for Numerical and Analytical Methods in Geomechanics, 2, pp. 189-197.

$1979 a$. An energy estimate of the flexural behaviour of a circular foundation embedded in an isotropic elastic medium. International Journal for Numerical and Analytical Methods in Geomechanics, 3, pp. 285-292.

$1979 b$. On the displacement of a rigid circular disc embedded in a transversely isotropic elastic medium. Solid Mechanics Archives, 5, pp. 163-172.

Selvadurai, A. P. S., and Nicholas, T. J. 1979. A theoretical assessment of the screw plate test. Proceedings, 3rd International Conference on Numerical Methods in Geomechanics, Aachen, Germany, Vol. 3, pp. 1245-1252.

Selvadurai, A. P. S., Nicholas, T. J., and Moore, B. F. 1980. Some experimental studies concerning the screw plate test. (Unpublished.)

Selvadurai, A. P. S., and Szymanski, M. B. 1980. The bearing capacity of rigid circular anchor plates embedded in an ideal cohesive soil. (Unpublished.)

SHield, R. T. 1955. On the plastic flow of metals under conditions of axial symmetry. Proceedings of the Royal Society of London, Series A, 233, pp. 267-287.

SkEMPTON, A. W. 1951. Bearing capacity of clays. Proceedings of the Building Research Congress, 1, pp. 180-189.

Sutherland, H. B. 1975. Granular materials: Review paper. Proceedings, Conference on Settlement of Structures, Cambridge, England, pp. 473-499.

WROTH, C. P. 1975. In situ measurement of initial stresses and deformation characteristics. Proceedings, ASCE Specialty Conference on In Situ Measurement of Soil Properties, Raleigh, NC, Vol. 2, pp. 181-231. 